\title{
Predicting post-traumatic stress disorder: validation of the Trauma Screening Questionnaire in victims of assault
}

\author{
JAMES T. R. WALTERS ${ }^{1}$, JONATHAN I. BISSON ${ }^{1 *}$ AND JONATHAN P. SHEPHERD ${ }^{2}$ \\ ${ }^{1}$ Department of Psychological Medicine, Cardiff University, Monmouth House, University Hospital of Wales, \\ Cardiff, UK; ${ }^{2}$ Department of Oral and Maxillofacial Surgery, Cardiff University, Dental School, Cardiff, UK
}

\begin{abstract}
Background. No accurate means of determining which individuals will develop post-traumatic stress disorder (PTSD) following a traumatic event has yet been identified. This study aimed to determine the validity of the Trauma Screening Questionnaire (TSQ) in predicting the development of PTSD following assault.
\end{abstract}

Method. Five hundred and sixty-two individuals who presented to an emergency unit following assault completed the TSQ between 1 and 3 weeks later. The Davidson Trauma Scale (DTS) was completed by the same individuals at 1 month and 6 months following assault to determine the presence of PTSD. The predictive power of the TSQ was determined by statistical tests.

Results. The TSQ was an effective means of predicting future PTSD, with a sensitivity of $0 \cdot 85$, specificity 0.89 , negative predictive value (NPV) 0.98 and efficiency 0.90 . The positive predictive value (PPV) was lower $(0 \cdot 48)$, probably as a result of the relatively low prevalence of PTSD at 1 month $(11 \%)$ and 6 months $(8 \%)$ following the assault.

Conclusions. This study suggests that the TSQ can be used between 1 and 3 weeks after assault to help identify individuals who will develop PTSD.

\section{INTRODUCTION}

One of the most pertinent and enduring questions in the field of traumatic stress research is how to predict those who will go on to develop post-traumatic stress disorder (PTSD) following a traumatic event. This holy grail of prediction has been made all the more alluring by the emergence of several treatment approaches that may halt the progression of traumatic stress symptoms to chronic PTSD (Bryant et al. 2003 a; Ehlers et al. 2003; Davidson, 2004; National Collaborating Centre for Mental Health, 2005). By identifying those likely to develop PTSD, predictive screening instruments may be most valuable in ensuring the

\footnotetext{
* Address for correspondence: Dr Jonathan I. Bisson, Department of Psychological Medicine, Cardiff University, Monmouth House, University Hospital of Wales, Heath Park, Cardiff CF14 4XW, UK.

(Email: bissonji@cf.ac.uk)
}

appropriate and selective use of early interventions, given the potentially harmful effect of non-selective approaches (Rose et al. 2005).

A wide spectrum of candidate predictors has been examined. These include potential risk factors present before, during and after the trauma and range from demographic to symptomatic and biological variables (Bryant, 2003). Two systematic reviews suggest that peri- and post-traumatic variables, including trauma severity, perceived life threat, dissociation, reported lack of social support after the traumatic event and subsequent life events, have the strongest association with PTSD but have limited value as individual predictors (Brewin et al. 2000; Ozer et al. 2003). Pre-existing vulnerability factors such as history of psychiatric disorder, genetic liability or gender were shown to be weaker predictive factors. More recently, pre- and peri-traumatic factors such as 
pretraumatic hostility and low level of selfefficacy (Heinrichs et al. 2005) as well as reaction to the trauma, in particular panic attacks (Nixon \& Bryant, 2003), have been shown to predict the development of PTSD. These and other studies have also considered biological markers, including heart rate and cortisol, with mixed results (Blanchard et al. 2002; Bryant et al. 2003 b); Heinrichs et al. 2005). Protective features have also been identified, such as resilience and recovery factors (e.g. 'hardiness'), that lessen the chances of developing PTSD following a trauma (King et al. 1999). Factors linked to cultural influences, social context and help-seeking behaviour are less amenable to quantitative measurement than many biomedical variables but nonetheless could also influence outcome.

Further predictive candidates are the individual symptoms and symptom clusters following a traumatic event. Identifying and addressing such precursor symptoms has been termed 'indicated prevention' and could provide a new and valuable means of treating PTSD. However, the roles of different types of symptoms remain largely unknown (Zatzick et al. 2002; Bryant, 2003). The role of dissociation symptoms in predicting future PTSD has been disputed, although there is good evidence to suggest an association between peritraumatic dissociation and development of PTSD (Ozer et al. 2003). Persistent dissociation may be more useful than peritraumatic dissociation in predicting PTSD (Panasetis \& Bryant, 2003; Briere et al. 2005), although this issue is as yet unresolved.

The introduction of the Acute Stress Disorder (ASD) diagnosis (APA, 1994), while independent of PTSD, potentially introduced a reliable predictive diagnosis for later PTSD. However, the usefulness of this diagnosis in achieving this aim has now been widely questioned (Bryant, 2003; Creamer et al. 2004). Bryant (2003) reviewed 10 prospective studies of ASD to determine if it was predictive of chronic PTSD. The proportion that went on to develop PTSD ranged from $30 \%$ to $83 \%$ at 6 months; the proportion of those with PTSD at 6 months who had also had ASD ranged from $10 \%$ to $61 \%$.

Several screening tools aimed at identifying patients who have PTSD, prior to formal diagnosis by clinical interview, have now been developed, as reviewed by Brewin (2005). These range from simple four-item tools such as the SPAN (Startle, Physiological arousal, Anger and Numbness) (Meltzer-Brody et al. 1999), to more complex scales (Foa et al. 1997). Brewin (2005) found that few of these scales had been validated in large and diverse populations or tested independently. Notably, he also suggested that shorter, simpler scales may perform as well as, if not better than, longer and more complex measures. The Trauma Screening Questionnaire (TSQ) was singled out, along with the Impact of Event Scale (Horowitz et al. 1979), as having consistently performed well in diagnostic prediction, as well as having been validated on independent samples. The SPAN has also been tested on varying independent populations with comparable results (Chen et al. 2003; Meltzer-Brody et al. 2004).

The TSQ is a simple 10-item instrument that has undergone initial validation in different populations within the same study and shows promise in assessments of reliability and validity (Brewin et al. 2002). The study reported here was designed to evaluate the TSQ as a means of predictive screening for future PTSD in victims of assault.

\section{METHOD}

\section{Subjects}

Subjects were consecutive patients over 16 years of age who, over an 18-month period, attended the University Hospital of Wales' Emergency Unit following an assault and were able to complete an English-language questionnaire. No further exclusion criteria were applied. Demographic details including age, sex and employment status were recorded at initial interview as well as type (soft tissue or fracture) and location of injury, presence of alcohol consumption within 6 hours and self-reported police involvement. After complete description of the study to the subjects, written informed consent was obtained. Fig. 1 shows recruitment and participant numbers.

\section{Measures}

The TSQ was adapted from the PTSD Symptom Scale - Self-Report Version (Foa et al. 1993). It is a 10 -item scale and is answered with binary 


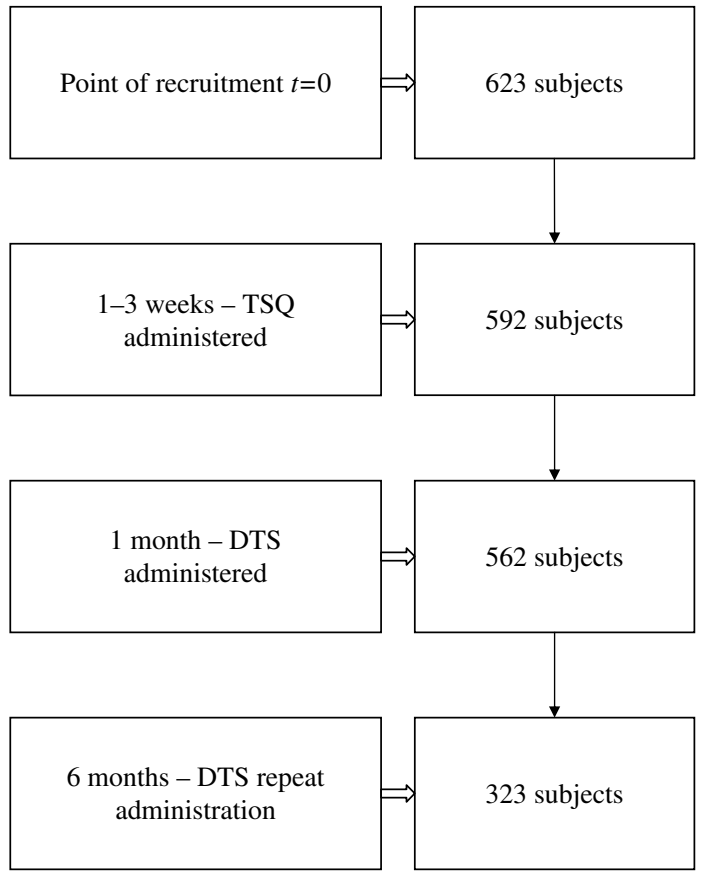

FIG. 1. Subjects followed-up from recruitment.

'yes/no' responses. The full range of cut-off scores that were examined in the initial study (Brewin et al. 2002) were also tested in the analysis here and ranged from three to seven items.

The diagnosis of PTSD was made using the Davidson Trauma Scale (DTS) (Davidson et al. 1997). This 17-item self-report questionnaire includes all PTSD symptom clusters; respondents are considered to have PTSD if they score at least one re-experiencing, three avoidance/ numbing and two hyperarousal phenomena at a frequency of at least twice in the previous week. It is a reliable and validated instrument in the diagnosis of PTSD (Zlotnick et al. 1996; Davidson et al. 1997, 2002).

\section{Procedure}

Once recruited and having completed the initial interview, subjects were contacted by telephone 1 to 3 weeks (median 13 days, range 6-21 days) after the assault and the TSQ was administered by a nurse trained in its use. If telephone completion was not possible, the questionnaire was sent by mail with completion instructions and a return-addressed envelope. A contact number was provided for further assistance if required.

Subjects were subsequently contacted 1 and 6 months after the assault and asked to complete the DTS. All possible efforts were made to follow-up subjects, by means of forwarding addresses and general practitioner or other contacts as appropriate.

All subjects were provided with information regarding Victim Support services for emotional support, assistance with compensation claims, and practical help. Those who scored positively on the DTS were offered an assessment appointment with the local traumatic stress service.

\section{Statistical methods}

The efficacy of the TSQ in predicting a subsequent diagnosis of PTSD at 1 and 6 months was measured in terms of sensitivity and specificity. Sensitivity indicates the probability that someone with PTSD would have tested positive on the TSQ; specificity refers to the probability that someone without PTSD would have tested negative on the TSQ. Positive (PPV) and negative predictive values (NPV) were also determined. These are the proportions of those who test positive on the TSQ who go on to develop PTSD and who test negative on TSQ who do not develop PTSD. The overall efficiency of the different cut-offs was also calculated. This is a measure of the performance of the test that describes the percentage of those correctly identified as having or not having PTSD.

\section{RESULTS}

Fig. 1 shows study attrition rates. The subjects for whom no follow-up data were available, due to questionnaire non-completion or incomplete data availability, did not differ from the overall sample in relation to age, gender and employment. Because of ethical restrictions in data collection, no demographic details are available for the 122 people who declined to participate in the study at the outset.

The subjects for whom full data were available, including the TSQ and DTS at 1 month, were considered as the study population. This population consisted of 562 subjects, 476 $(84.7 \%)$ of whom were male. The average age 
Table 1. Sensitivity, specificity and predictive values of symptom scores at 1 month

\begin{tabular}{|c|c|c|c|c|c|c|}
\hline $\begin{array}{l}\text { Number of } \\
\text { symptoms }\end{array}$ & $\begin{array}{l}\text { Number } \\
\text { meeting criteria }\end{array}$ & Sensitivity & Specificity & $\begin{array}{c}\text { Positive } \\
\text { predictive value }\end{array}$ & $\begin{array}{l}\text { Negative } \\
\text { predictive value }\end{array}$ & Efficiency \\
\hline $\begin{array}{l}\text { At least } 3 \\
\text { re-experiencing }\end{array}$ & 95 & $0 \cdot 68$ & $0 \cdot 89$ & $0 \cdot 44$ & $0 \cdot 96$ & $0 \cdot 87$ \\
\hline $\begin{array}{l}\text { At least } 4 \\
\text { re-experiencing }\end{array}$ & 37 & $0 \cdot 29$ & $0 \cdot 96$ & $0 \cdot 49$ & $0 \cdot 92$ & $0 \cdot 89$ \\
\hline At least 3 arousal & 168 & $0 \cdot 94$ & $0 \cdot 78$ & $0 \cdot 36$ & $0 \cdot 99$ & $0 \cdot 80$ \\
\hline At least 4 arousal & 100 & $0 \cdot 73$ & $0 \cdot 89$ & $0 \cdot 45$ & $0 \cdot 96$ & $0 \cdot 87$ \\
\hline $\begin{array}{l}\text { At least } 5 \\
\text { re-experiencing or arousal }\end{array}$ & 138 & $0 \cdot 84$ & $0 \cdot 92$ & $0 \cdot 41$ & 0.99 & $0 \cdot 85$ \\
\hline $\begin{array}{l}\text { At least } 6 \\
\text { re-experiencing or arousal }\end{array}$ & 110 & $0 \cdot 85$ & $0 \cdot 89$ & $0 \cdot 48$ & $0 \cdot 98$ & $0 \cdot 90$ \\
\hline $\begin{array}{l}\text { At least } 7 \\
\text { re-experiencing or arousal }\end{array}$ & 83 & $0 \cdot 92$ & $0 \cdot 69$ & $0 \cdot 52$ & $0 \cdot 96$ & $0 \cdot 90$ \\
\hline
\end{tabular}

Bold values represent the optimum cut-off scores in the Brewin et al. (2002) study.

Table 2. Sensitivity, specificity and predictive values of symptom scores at 6 months

\begin{tabular}{|c|c|c|c|c|c|c|}
\hline $\begin{array}{l}\text { Number of } \\
\text { symptoms }\end{array}$ & $\begin{array}{l}\text { Number } \\
\text { meeting criteria }\end{array}$ & Sensitivity & Specificity & $\begin{array}{c}\text { Positive } \\
\text { predictive value }\end{array}$ & $\begin{array}{c}\text { Negative } \\
\text { predictive value }\end{array}$ & Efficiency \\
\hline $\begin{array}{l}\text { At least } 3 \\
\text { re-experiencing }\end{array}$ & 43 & $0 \cdot 96$ & 0.79 & $0 \cdot 26$ & 0.99 & 0.88 \\
\hline $\begin{array}{l}\text { At least } 4 \\
\text { re-experiencing }\end{array}$ & 17 & 0.57 & $0 \cdot 90$ & $0 \cdot 30$ & $0 \cdot 96$ & $0 \cdot 91$ \\
\hline At least 3 arousal & 87 & $0 \cdot 87$ & $0 \cdot 78$ & $0 \cdot 23$ & $0 \cdot 99$ & $0 \cdot 78$ \\
\hline At least 4 arousal & 49 & $0 \cdot 70$ & 0.89 & $0 \cdot 33$ & 0.97 & $0 \cdot 88$ \\
\hline $\begin{array}{l}\text { At least } 5 \\
\text { re-experiencing or arousal }\end{array}$ & 68 & $0 \cdot 84$ & 0.87 & $0 \cdot 29$ & $0 \cdot 99$ & $0 \cdot 84$ \\
\hline $\begin{array}{l}\text { At least } 6 \\
\text { re-experiencing or arousal }\end{array}$ & 54 & $0 \cdot 88$ & 0.78 & $0 \cdot 33$ & 0.98 & $0 \cdot 87$ \\
\hline $\begin{array}{l}\text { At least } 7 \\
\text { re-experiencing or arousal }\end{array}$ & 38 & $0 \cdot 92$ & 0.61 & $0 \cdot 37$ & $0 \cdot 97$ & $0 \cdot 90$ \\
\hline
\end{tabular}

Bold values represent the optimum cut-off scores in the Brewin et al. (2002) study.

was 26 years (s.D. $=9 \cdot 05)$. Three hundred and sixty-five $(64.9 \%)$ of the study population were employed, $141(25 \cdot 1 \%)$ were students, 50 $(8.9 \%)$ unemployed and six $(1 \cdot 1 \%)$ retired. Two hundred and fourteen $(38.1 \%)$ had soft-tissue facial or head injuries, $88(15 \cdot 7 \%)$ facial fractures and one $(0.2 \%)$ a skull fracture. Two hundred and three $(36 \cdot 1 \%)$ had other minor injuries, with $34(6 \%)$ having other fractures and $22(3.9 \%)$ multiple injuries that were judged to be severe by the assessing physician. A positive self-report of alcohol consumption was found in $528(94 \%)$ and there was self-reported police involvement in $214(38 \cdot 1 \%)$.

Tables 1 and 2 show the results for different cut-off score values for prediction of PTSD at 1 and 6 months. The bold values in the tables represent the optimum cut-off scores in the Brewin et al. (2002) study. This cut-off, of at least six re-experiencing or hyperarousal symptoms, also provided the best overall balance for sensitivity, specificity, overall efficiency and predictive values in this study population. Prevalence rates for PTSD were $11.0 \%$ at 1 month and $7 \cdot 7 \%$ at 6 months.

In this study the TSQ was administered at an earlier stage post-injury than in the Brewin et al. (2002) study. To assess whether the timing of administration of the questionnaire influenced its predictive validity, we examined outcomes from those who completed the questionnaire before and after the median timing point (13 days post-injury, range 6-21 days). This entailed comparing those who completed the TSQ in the second week post-injury (from 6 to 13 days) to those who completed the TSQ in the third week post-injury (from 14 to 21 days). Table 3 shows that both groups performed similarly for the optimum TSQ cut-off score of 6 or over at 1 and 6 months post-injury. 
Table 3. Median split analysis of outcomes at 1 and 6 months at optimum TSQ cut-off of 6

\begin{tabular}{|c|c|c|c|c|c|c|c|}
\hline & $\begin{array}{l}\text { Timing of TSQ } \\
\text { administration }\end{array}$ & $\begin{array}{c}\text { Number } \\
\text { meeting criteria }\end{array}$ & Sensitivity & Specificity & $\begin{array}{c}\text { Positive } \\
\text { predictive value }\end{array}$ & $\begin{array}{c}\text { Negative } \\
\text { predictive value }\end{array}$ & Efficiency \\
\hline \multirow{2}{*}{$\begin{array}{l}\text { Results for } \\
\text { 1-month } \\
\text { follow-up }\end{array}$} & $\begin{array}{r}\text { Second week } \\
\text { post-assault }\end{array}$ & 64 & $0 \cdot 88$ & $0 \cdot 86$ & $0 \cdot 55$ & $0 \cdot 98$ & $0 \cdot 87$ \\
\hline & $\begin{array}{l}\text { Third week } \\
\text { post-assault }\end{array}$ & 43 & $0 \cdot 81$ & $0 \cdot 90$ & $0 \cdot 49$ & 0.98 & $0 \cdot 89$ \\
\hline \multirow{2}{*}{$\begin{array}{l}\text { Results for } \\
6 \text {-month } \\
\text { follow-up }\end{array}$} & $\begin{array}{r}\text { Second week } \\
\text { post-assault }\end{array}$ & 32 & $0 \cdot 77$ & $0 \cdot 86$ & $0 \cdot 32$ & $0 \cdot 98$ & $0 \cdot 85$ \\
\hline & $\begin{array}{l}\text { Third week } \\
\text { post-assault }\end{array}$ & 22 & $0 \cdot 80$ & $0 \cdot 90$ & $0 \cdot 36$ & 0.98 & 0.90 \\
\hline
\end{tabular}

TSQ, Trauma Screening Questionnaire.

We also compared those with possible brain injuries to those without by (i) grouping together those with facial or skull fractures compared to those without and (ii) comparing those with any head injury to those without. The TSQ performed comparatively on all measures in these injury groups.

\section{DISCUSSION}

\section{Main findings}

This study represents the first large-scale independent validation of the TSQ as a brief screening instrument that may be useful in predicting later PTSD. The TSQ performed well in terms of sensitivity and specificity at both 1 and 6 months. Overall efficiency and NPV were high. The only apparent drawback was the low PPV, meaning that one in two individuals scoring positive on the TSQ would not meet the criteria for PTSD at 1 month and one in three would not do so at 6 months. However, predictive values are dependent upon prevalence levels of the conditions under consideration. The prevalence rates in this study of $11 \%$ at 1 month and $7.7 \%$ at 6 months are relatively low when compared to other samples (Kessler et al. 1995; Brewin et al. 2003). This low prevalence rate would serve to lower the PPV and in samples with a more typical prevalence the PPV would be higher.

There are two particular factors that might explain the low prevalence rates of PTSD in this study: (i) the high percentage of males in the sample, and (ii) the high percentage of those who reported alcohol consumption prior to the assault. Both these factors have been associated with reduced risk of developing PTSD (Kessler et al. 1995; Maes et al. 2001). Low prevalence rates could also reflect under-reporting of symptoms.

The reduction in prevalence rates over time is consistent with the natural history of PTSD (Rothbaum \& Foa, 1992) and may have been influenced by many variables, including the fact that some individuals would have received treatment for PTSD or could have been in touch with Victim Support services between 1 and 6 months.

The results suggest that those at risk of developing PTSD can be identified before 3 weeks after the traumatic event using the TSQ. In the original study Brewin et al. (2002) recommended waiting until 3 weeks to administer the TSQ to allow for natural recovery processes, but the results of this study were equivalent to those of Brewin et al. (2002). Furthermore, it seems to be possible to screen as early as the second week post-injury, this offering comparable outcomes to later screenings both in this (see Table 3) and the original Brewin et al. study.

The results compare very favourably with other studies of predictive tests for the future development of PTSD (e.g. Shalev et al. 1997; Bryant, 2003) and to screening tests for the presence of PTSD (Breslau et al. 1999; MeltzerBrody et al. 1999; Connor \& Davidson, 2001). They are also consistent with the position of Creamer et al. (2004), who questioned the predictive validity of ASD as a result of the dissociative criteria, but supported the predictive validity of re-experiencing and hyperarousal symptoms.

The fact that the optimum cut-off score of 6 or above was the same as that in the original 
study adds to the authority of validation of the TSQ.

\section{Strengths and weaknesses}

The major strengths of this study are the large sample size and high retention rates. Ninety-five per cent of individuals who completed the TSQ completed the DTS at 1 month and $56 \%$ did so at 6 months. These rates are at least equivalent if not superior to many previous studies of similar populations of assault victims (Birmes et al. 2003; Brewin, 2005). The recruitment and follow-up methodology used was stringent and is a further strength, particularly the telephone interviews and written contacts, which have both been shown to be valid data collection methods that reduce attrition to a minimum (Zatzick et al. 2002).

The sample consisted of $84 \cdot 7 \%$ males and $94 \%$ of participants had consumed alcohol. Although these figures are probably a fair reflection of the population admitted to Accident and Emergency Departments with assault, they do limit the generalizability of the results. Other weaknesses of the study include the absence of a clinical interview to verify PTSD and lack of follow-up beyond 6 months, although the usefulness of a predictive screening instrument beyond 6 months is debatable.

The DTS as a diagnostic tool for PTSD does not include an assessment of the 'stressor criterion' necessary for a diagnosis of PTSD (APA, 1994). We did not collect such data although we consider it likely that the majority of participants would fulfil both the subjective and objective stressor criteria given the nature of the assaults. If this is not the case then this effect would have inflated the apparent PTSD prevalence rate and this possibility needs to be considered in interpreting the findings.

We did not specifically exclude brain injury or cognitive impairment but do not envisage that many, if any, subjects suffered significant brain injury given the nature of the injuries reported and because all subjects were required to answer questions at initial interview and complete a telephone interview or questionnaire 1-3 weeks later. Given that traumatic brain injury has been reported to influence the development of PTSD (Harvey et al. 2003), we further examined this issue, as best we could, by including an analysis of the one individual who sustained a skull fracture and those who sustained facial fractures compared to those without these injuries. The results indicated that the TSQ performed similarly in both groups, thus it would seem valid to use the TSQ in both these injury groups.

No further subgroup analysis was performed, which could mean that potentially important predictive factors or differing effects of prediction between groups were missed. However, subgroup and multiple analyses have the disadvantage of decreased statistical power.

\section{Validity of the TSQ}

Validating psychiatric instruments has long been considered a difficult task given the lack of any definite psychopathological gold standards for comparison. We accept that the ideal methodology would be to compare the TSQ to the recognized gold standard of diagnostic interview to diagnose PTSD, but this was not possible given resource limitations.

This study confirms concurrent validity between the TSQ and DTS. The validity of the TSQ in predicting PTSD rests with the DTS being a validated diagnostic instrument for PTSD. The evidence suggests the DTS is a pragmatic and valid instrument to diagnose PTSD (Zlotnick et al. 1996; Davidson et al. 1997, 2002), having been widely used in research settings. Given these arguments we feel it is reasonable to consider the DTS as a comparator against which the TSQ can be validated, while accepting that clinical interviews would have further bolstered the process of validation. The agreement between the prediction of PTSD by the TSQ and subsequent positive result on DTS indicates good concurrent and predictive validity. As recommended by Brewin et al. (2002), further investigations are needed to validate this instrument as a predictive or screening instrument for PTSD in different populations and settings.

\section{Clinical implications}

On the basis of these findings, the TSQ has potential as part of a PTSD predictive screening and treatment regime. The UK National Screening Committee has set 22 criteria for appraising the viability, effectiveness and appropriateness of a screening programme (www.nsc.nhs.uk/pdfs/criteria.pdf). The TSQ 
addresses the four criteria that are relevant to such a screening tool, namely (i) the test should be simple, safe, precise and validated, (ii) the distribution of test values in the target population should be known and a suitable cut-off level defined and agreed, (iii) the test should be acceptable to the population, and (iv) there should be an agreed policy on the further diagnostic investigation of individuals with a positive test result and on the choices available to those individuals.

The TSQ appears to be acceptable, simple and safe, which means that minimal staff training is required and that there is potential for valid translation into other languages. This study adds to the growing evidence in differing settings and populations suggesting that the TSQ is a valid instrument to screen for PTSD. Distribution of test values in the target population is known and a suitable cut-off level has now been defined and agreed. In addition, the test is acceptable to the relevant population. The next step is to develop and agree policy on any necessary further diagnostic investigation of those who screen positive. In practice, a faceto-face mental health evaluation to determine the presence of PTSD is the likely additional step.

The TSQ now requires further evaluation as a predictive screening test in other populations. The validity of such studies would be bolstered by using interviews to confirm diagnosis of PTSD. If reliability and validity remain high, it should be evaluated in conjunction with evidence-based interventions such as early trauma focused cognitive behavioural therapy (CBT) for those with PTSD (Ehlers et al. 2003), through randomized controlled trials to determine whether screening programmes are effective in reducing the morbidity associated with PTSD. The further development of predictive instruments such as the TSQ should enhance the evolution of the innovative, targeted, preventive treatments for PTSD that are emerging and help to lessen the burden of this distressing condition.

\section{ACKNOWLEDGEMENTS}

We are grateful to all the staff at the University Hospital of Wales' Emergency Unit involved in collecting the data for this study.

\section{DECLARATION OF INTEREST}

None.

\section{REFERENCES}

APA (1994). Diagnostic and Statistical Manual of Mental Disorders (4th edn) (DSM-IV). American Psychiatric Press: Washington, DC.

Birmes, P., Brunet, A., Carreras, D., Ducasse, J. L., Charlet, J. P., Lauque, D., Sztulman, H. \& Schmitt, L. (2003). The predictive power of peritraumatic dissociation and acute stress symptoms for posttraumatic stress symptoms: a three-month prospective study. American Journal of Psychiatry 160, 1337-1339.

Blanchard, E. B., Hickling, E. J., Galovski, T. \& Veazey, C. (2002). Emergency room vital signs and PTSD in a treatment seeking sample of motor vehicle accident survivors. Journal of Traumatic Stress 15, 199-204.

Breslau, N., Peterson, E. L., Kessler, R. C. \& Schultz, L. R. (1999). Short screening scale for DSM-IV posttraumatic stress disorder. American Journal of Psychiatry 156, 908-911.

Brewin, C. R. (2005). Systematic review of screening instruments for adults at risk of PTSD. Journal of Traumatic Stress 18, 53-62.

Brewin, C. R., Andrews, B. \& Rose, S. (2003). Diagnostic overlap between acute stress disorder and PTSD in victims of violent crime. American Journal of Psychiatry 160, 783-785.

Brewin, C. R., Andrews, B. \& Valentine, J. D. (2000). Meta-analysis of risk factors for posttraumatic stress disorder in trauma-exposed adults. Journal of Consulting and Clinical Psychology 68, 748-766.

Brewin, C. R., Rose, S., Andrews, B., Green, J., Tata, P., McEvedy, C., Turner, S. \& Foa, E. (2002). Brief screening instrument for post-traumatic stress disorder. British Journal of Psychiatry 181, $158-162$.

Briere, J., Scott, C. \& Weathers, F. (2005). Peritraumatic and persistent dissociation in the presumed etiology of PTSD. American Journal of Psychiatry 162, 2295-2301.

Bryant, R. A. (2003). Early predictors of posttraumatic stress disorder. Biological Psychiatry 53, 789-795.

Bryant, R. A., Harvey, A. G., Guthrie, R. M. \& Moulds, M. L. $(2003 b)$. Acute psychophysiological arousal and posttraumatic stress disorder: a two-year prospective study. Journal of Traumatic Stress 16, 439-443.

Bryant, R. A., Moulds, M. L. \& Nixon, R. V. D. (2003a). Cognitive behaviour therapy of acute stress disorder: a four-year follow-up. Behaviour Research and Therapy 41, 489-494.

Chen, C. H., Shen, W. W., Tan, H. K., Chou, J. Y. \& Lu, M. L. (2003). The validation study and application of stratum-specific likelihood ratios in the Chinese version of SPAN. Comprehensive Psychiatry 44, 78-81.

Connor, K. M. \& Davidson, J. R. (2001). SPRINT: a brief global assessment of post-traumatic stress disorder. International Clinical Psychopharmacology 16, 279-284.

Creamer, M., O'Donnell, M. L. \& Pattison, P. (2004). The relationship between acute stress disorder and posttraumatic stress disorder in severely injured trauma survivors. Behaviour Research and Therapy 42, 315-328.

Davidson, J. R. (2004). Long-term treatment and prevention of posttraumatic stress disorder. Journal of Clinical Psychiatry $\mathbf{6 5}$ (Suppl. 1), 44- 48 .

Davidson, J. R., Book, S. W., Colket, J. T., Tupler, L. A., Roth, S., David, D., Hertzberg, M., Mellman, T., Beckham, J. C., Smith, R. D., Davison, R. M., Katz, R. \& Feldman, M. E. (1997). Assessment of a new self-rating scale for post-traumatic stress disorder. Psychological Medicine 27, 153-160.

Davidson, J. R., Tharwani, H. M. \& Connor, K. M. (2002). Davidson Trauma Scale (DTS): normative scores in the general population and effect sizes in placebo-controlled SSRI trials. Depression and Anxiety 15, 75-78.

Ehlers, A., Clark, D. M., Hackmann, A., McManus, F., Fennell, M., Herbert, C. \& Mayou, R. (2003). A randomized controlled trial of 
cognitive therapy, a self-help booklet, and repeated assessments as early interventions for posttraumatic stress disorder. Archives of General Psychiatry 60, 1024-1032.

Foa, E. B., Cashman, L., Jaycox, L. \& Perry, K. (1997). The validation of a self-report measure of posttraumatic stress disorder: the Posttraumatic Diagnostic Scale. Psychological Assessment 9, 445-451.

Foa, E. B., Riggs, D. S., Dancu, C. V. \& Rothbaum, B. O. (1993). Reliability and validity of a brief instrument for assessing posttraumatic stress disorder. Journal of Traumatic Stress 6, 459-473.

Harvey, A. G., Brewin, C. R., Jones, C. \& Kopelman, M. D. (2003). Coexistence of posttraumatic stress disorder and traumatic brain injury: towards a resolution of the paradox. Journal of the International Neuropsychological Society 9, 663-676.

Heinrichs, M., Wagner, D., Schoch, W., Soravia, L. M., Hellhammer, D. H. \& Ehlert, U. (2005). Predicting posttraumatic stress symptoms from pretraumatic risk factors: a 2-year prospective follow-up study in firefighters. American Journal of Psychiatry $\mathbf{1 6 2}$, 2276-2286.

Horowitz, M. J., Wilner, N. \& Alvarez, W. (1979). Impact of Event Scale: a measure of subjective stress. Psychosomatic Medicine 41, 209-218.

Kessler, R. C., Sonnega, A., Bromet, E., Hughes, M. \& Nelson, C. B. (1995). Posttraumatic stress disorder in the National Comorbidity Survey. Archives of General Psychiatry 52, 1048-1060.

King, D. W., King, L. A., Foy, D. W., Keane, T. M. \& Fairbank, J. A. (1999). Posttraumatic stress disorder in a national sample of female and male Vietnam veterans: risk factors, war-zone stressors, and resilience-recovery variables. Journal of Abnormal Psychology 108, 164-170.

Maes, M., Delmeire, L., Mylle, J. \& Altamura, C. (2001). Risk and preventive factors of post-traumatic stress disorder (PTSD): alcohol consumption and intoxication prior to a traumatic event diminishes the relative risk to develop PTSD in response to that trauma. Journal of Affective Disorders 63, 113-121.

Meltzer-Brody, S., Churchill, E. \& Davidson, J. R. T. (1999) Derivation of the SPAN, a brief diagnostic screening test for posttraumatic stress disorder. Psychiatry Research 88, 63-70.
Meltzer-Brody, S., Hartmann, K., Miller, W. C., Scott, J., Garrett, J. \& Davidson, J. (2004). A brief screening instrument to detect posttraumatic stress disorder in outpatient gynecology. Obstetrics and Gynecology 104, 770-776.

National Collaborating Centre for Mental Health (2005). PostTraumatic Stress Disorder: The Management of PTSD in Adults and Children in Primary and Secondary Care. National Institute of Clinical Excellence (Gaskell): London and British Psychological Society: Leicester.

Nixon, R. D. \& Bryant, R. A. (2003). Peritraumatic and persistent panic attacks in acute stress disorder. Behaviour Research and Therapy 41, 1237-1242.

Ozer, E. J., Best, S. R., Lipsey, T. L. \& Weiss, D. S. (2003). Predictors of posttraumatic stress disorder and symptoms in adults: a meta-analysis. Psychological Bulletin 129, 52-73.

Panasetis, P. \& Bryant, R. A. (2003). Peritraumatic versus persistent dissociation in acute stress disorder. Journal of Traumatic Stress 16, 563-566.

Rose, S., Bisson, J., Churchill, R. \& Wessely, S. (2005). Psychological debriefing for preventing post traumatic stress disorder (PTSD). Cochrane Database of Systematic Reviews. Art. No.: CD00560. doi:10.1002/14651858.CD000560. The Cochrane Library (2).

Rothbaum, B. O. \& Foa, E. B. (1992). Subtypes of posttraumatic stress disorder and duration of symptoms. In Posttraumatic Stress Disorder: DSM-IV and Beyond (ed. J. R. T. Davidson and E. B. Foa), pp. 23-35. American Psychiatric Press: Washington, DC.

Shalev, A. Y., Freedman, S., Peri, T., Brandes, D. \& Sahar, T. (1997). Predicting PTSD in trauma survivors: prospective evaluation of self-report and clinician-administered instruments. British Journal of Psychiatry 170, 558-564.

Zatzick, D. F., Kang, S. M., Muller, H. G., Russo, J. E., Rivara, F. P., Katon, W., Jurkovich, G. J. \& Roy-Byrne, P. (2002). Predicting posttraumatic distress in hospitalized trauma survivors with acute injuries. American Journal of Psychiatry 159, 941-946.

Zlotnick, C., Davidson, J., Shea, M. T. \& Pearlstein, T. (1996) Validation of the Davidson Trauma Scale in a sample of survivors of childhood sexual abuse. Journal of Nervous and Mental Disease 184, 255-257. 